\title{
İş Yerlerinde Ergonomik Koşulların İş Sağlığı ve Güvenliği Açısından Aydınlatma Özelinde Değerlendirilmesi
}

\author{
Lighting Assessment of Ergonomic Conditions in Workplaces in Terms of Occupational \\ Health and Safety
}

\author{
İpek OKŞAK ${ }^{1} \mathbb{1}$, Orhan GÖKYAY ${ }^{2}$ \\ ${ }^{1}$ Marmara Üniversitesi, IŞ Güvenliği Ana Bilim Dal, İş Güvenliği Programı, İstanbul, TÜRKIYYE \\ ${ }^{2}$ Marmara Üniversitesi, Çevre Mühendisliği Bölümü,34722, Kadıköy/İstanbul, TÜRKIYYE
}

$\ddot{O} \mathbf{z}$

İs yerlerinde çalışanlardan daha fazla verim alınmak istenmesi ve kişilere daha güvenli ve sağlıklı bir çalıșma ortamı oluşturabilmek için günümüzde iş sağlığı ve güvenliğine (ISSG) verilen önem artmıştır. Bununla birlikte çalışanlar daha değerli hale gelmiş dolayısıyla ergonomi bilimine verilen önem de katlanmıştır. Ergonomi bilimi insan ile iş arasındaki bütün ilişkileri ve bu ilişkiyi etkileyen tüm faktörleri inceler. Çalışanların işe, işin çalışanlara daha uyumlu hale gelmesi ergonominin amacıdır. İkili uyumluluğun sağlanmasıyla beraber çalışanların zorlanmayacağı ve daha verimli olacağı düşünülmektedir.

Yapılan çalışmada farklı iş kollarından çeşitli çalışanlara anket uygulanmış ve iş yerlerinde ergonomik koşulların uygulanıp uygulanmadığı, iş güvenliğinin sağlanıp sağlanmadığı araştırılmıştır. Araştırmaya toplam 64 kişi katılmışır. Ergonomik koşullar üzerinde durulmuş, çalışanların sağlığ üzerinde ne tür etkiler yarattığı incelenmiştir.

$\mathrm{Bu}$ araştırmanın sonucunda çalışanların ergonomi ve ergonomik koşullarda oluşturulan iş yerleri hakkında bilgi sahibi olmadığı ortaya çıkmıştır. Ayrıca ofis ortamında kullanılan araç ve gereçlerin ergonomik koşullara uygun olmadığ belirlenmiştir. İşyerlerinde çalışanlar üzerinde aydınlatmanın yüksek önem taşıdığı fark edilmiştir. Aydınlatmanın düşük olduğu alanlarda çalışanların sağlığının olumsuz etkilendiği ve iş kazası oranlarında artış olduğu gözlenmiştir.

Anahtar Kelimeler: Ergonomi, aydınlatma, İş kazası, İș sağlığı ve güvenliği

\begin{abstract}
The importance given to occupational health and safety (OHS) has increased today in order to get more efficiency from the employees at workplaces and to create a safer and healthier working environment for people. Moreover, employees have become more valuable therefore the importance given to the science of ergonomics has also increased. Ergonomics examines all the relationships between human and work and all factors affecting this relationship. The purpose of ergonomics is to make the employees more compatible with the job and the job to the employees. It is believed that the employees will not have difficulties and will be more efficient with ensuring bilateral compatibility.
\end{abstract}

In the study, a questionnaire was applied to various employees from different business lines and it was investigated whether ergonomic conditions were applied in the workplaces and work safety was ensured. A total of 64 people participated in the study. Ergonomic conditions were emphasized, and what kind of effects they have on employees' health was examined.

As a result, it has been revealed that the employees do not have knowledge about ergonomics and workplaces created under ergonomic conditions. In addition, it has been determined that the tools and equipment used in the office environment were not suitable for ergonomic conditions. It has been noticed that lighting has a big importance on those employees in the workplace. It has been observed that the health of employees is negatively affected and there is an increase in occupational accident rates in areas with low illumination.

Keywords: Ergonomics, Lighting, occupational accident, occupational health and safety

\section{GİRIŞ VE AMAC}

Günümüz dünyası her alanda gelişmekte ve her gün yeni sektörler ortaya çıkmaktadır. Bununla birlikte çalışana olan ihtiyaç da artmıştır. İnsanlar vakitlerinin çoğunu işyerlerinde geçirmektedir ve bu çoğunluk yeteneklerine uygun olmayan şekilde iş yaptıklarını fark etmeden çalışmaktadır. Uygunsuz işyerleri sağlık ve güvenlik sorununu da beraberinde getirmekte ve çalışanların sosyal hayatını olumsuz etkilemektedir. Ergonomi faktörü 19'uncu yüzyılda ilk keşfedildiği zamanlara kıyasla şu an çok daha fazla önem görmektedir [1]. 
Ergonominin temel amacı çalışan ile iş arasındaki uyumu sağlamaktır. Ergonomik faktörler kişinin sağlığ ve güvenliği içim büyük önem taşırlar ayrıca unutulmamalıdır ki sağlıklı bir çalışan iş yerinde daha verimli olmaktadır. Teknolojinin gelişmesi ve işverenlerin çalışanlarına verdikleri değerin artmasıyla birlikte ergonomik uygulamalarla çalışanlardan alınan verimin arttırılması amaçlanmıştır. $\mathrm{Bu}$ çalışmalar arasında en çok önem ofis çalışmalarına verilmektedir çünkü günümüzde teknolojik gelişmelerin hızla artışına bağlı olarak masa başında geçirilen zaman artmıştır [1]. Ofislerin ve işyerlerinin düzeni tasarlanırken çalışanların rahatlığı, ortamın konforu ve havalandırılması, gürültüyü engellemek amaçlı gerekli ses yalıtımı yapılması ve aydınlatma gibi faktörler ön planda tutulmaktadır [2]. İnsan vücut 1Sısı çalışma ortamındaki sıcaklığa, neme ve iklime dayalı çevre koşullarına göre dengesini korumaya çalışır. $\mathrm{Bu}$ 1sı dengesi kanunla belirlenen değerlere uyulmasıyla mümkündür [3].

Ergonomi her işyeri için göz ardı edilmemesi gereken bir konudur. Çalışma sırasında sağlık açısından duruş bozukluğu, psikolojik olarak stres gibi olumsuzlukların önüne geçebilmek veya en aza indirgemek, üretilen ürünlerin kalitesi ve verimliliğine de doğrudan yansımaktadır. Ergonominin bir başka amacı da iş kazası ve meslek hastalıklarının önlenmek, çalışanların ruhsal ve fiziksel halini korumak hatta iyileştirmektir.

$\mathrm{Bu}$ çalışma işyerlerinde çalışanların iş sağlı̆̆ ve güvenliği açısından ergonomi hakkında ne kadar bilgi sahibi olduklarını ölçmeyi, yapılan anketlerle de ergonominin İSG açısından önemini göstermeyi amaçlamaktadır. Araştırmanın anketine katılım gösterenler ofis ve fabrika çalışanlarıdır. Çalışanlarda ergonominin ne derece önem teşkil ettiği, uygulanabilirliği ve iş sağlıği ve güvenliği açısından gerekliliği vurgulanmaya çalışılmıştır. Risk önlemlerinin genel çerçevede incelenmesi ve ergonomik risk faktörleri tanımlanarak, alınması gerekli önlemler başlıklar altında sıralanmıştır.

\section{MATERYAL VE YÖNTEM}

Yapılan araştırma İstanbul ilinde değişik sektörlerdeki işyerleri baz alınarak yapılmıştır. Farklı sektörlerden çalışanlar seçilerek ergonominin sektörden sektöre yarattığı etki izlenmek istenmiştir. Ankete katılan kişiler sahada ya da ofiste çalışmaktadır. Anket uzayı oluşturulurken iş çeşitliliği geniş tutularak araştırma için gerekli niteliklerin sağlanması amaçlanmıştır.

Çalışmada öznel değerlendirme yöntemi kullanılmıştır. Oluşturulan anket formunun ilk bölümü altı sorudan oluşmaktadır. Birinci bölümdeki sorular ankete katılanlar arasında genel bilgilerin edinildiği sorulardır.

Hazırlanan formun ikinci bölümü ise Beşli Likert Ölçekle hazırlanmıştır. Likert ölçek; herhangi bir katılımcının belirli bir ifade hakkındaki görüşlerini ölçmek amacı ile kullanılır. Likert aralıkları, katılımcılardan beklenen cevaplara göre beş, yedi veya dokuz seçeneğe sahip olabilir [5]. Bu bölümde işyerindeki çalışma ortamından kaynaklanan sorunlar ele alınmıştır ve aydınlatma yeterliliği incelenmiştir.

Son bölümde ise Likert ölçeği kullanılarak çalışma ortamında karşılaşılan rahatsızlıkların sıklığı ele alınmıştır. Her bir test için, MS Excel kullanılarak, ortalama kişi sayısı, ardından standart sapmalar hesaplanmıştır.

F testi yani varyans testi yardımıyla varyansların homojenlik gösterip göstermediği belirlenmiştir. Uygulanan teste göre $F_{\text {hesap }}$ aşağıdaki formülle $F_{\text {tablo }}$ ise MS Excel üzerinden FTERS formülü ile hesaplanmıştır.

$$
F_{\text {Hesap }}=\left(S_{\text {max }}\right)^{2}+\left(S_{\text {min }}\right)^{2}
$$

Yapılan bu hesap sonrasında $F_{\text {hesap }}$ değeri $F_{\text {tablo }}$ değerinden küçük ya da eşitse varyanslar homojendir sonucu çıkarılır eğer tam tersi durum olursa yani büyükse varyanslar homojen değildir.

Testin son k1smı olan hipotezler belirlenirken $T_{\text {hesap }}$ aşağıda belirtilmiş olan formülle hesaplanırken, $T_{\text {tablo }}$ ise MS Excel kullanılarak TTERS formülü ile hesaplanmıştır. Formülde yer alan X değeri ortalama kişi sayısını, S değeri ise standart sapmayı, $\mathrm{N}$ değeri de kişi sayısını göstermektedir.

$\mathrm{H}_{0}$ : Skor ortalamaları arasinda fark yoktur. $\left(\mu_{1}=\mu_{2}\right)$ $\mathrm{H}_{1}$ : Skor ortalamaları arasında fark vardır. $\left(\mu_{1} \neq \mu_{2}\right)$

$$
\begin{gathered}
S_{0}^{2}=\frac{\left(n_{1}-1\right) S_{1}^{2}+\left(n_{2}-1\right) S_{2}^{2}}{\left(n_{1}+n_{2}\right)-2} \\
T_{\text {hesap }}=\frac{\overline{X_{1}-X_{2}}}{\sqrt{\frac{s_{0}^{2}}{n_{1}}+\frac{s_{0}^{2}}{n_{2}}}}
\end{gathered}
$$

Eğer, $T_{\text {hesap }}$ değeri $\mathrm{T}_{\text {tablo }}$ değerinden küçük veya eşitse $H_{0}$ hipotezi kabul edilir ve ortalamalar arasında fark olmadığı sonucuna varılır. Eğer $T_{\text {hesap }}$ değeri büyükse tam tersi durum oluşur ve $H_{l}$ hipotezi kabul edilip ortalamalar arasında fark olduğu kabul edilir.

\section{BULGULAR VE TARTIŞMA}

Anket araştırmasına katılan kadın ve erkeklerin işyerlerinde çalışma şartları, sosyo-demografik özellikleri, sağlık konusunda yaşadıkları rahatsızlıklar, ergonomik rahatsılıklar, iş sağlı̆̆ ve güvenliği eğitimlerinin yapılma durumu gibi sorular sorulmuştur. Çıkan sonuçlar iki ortalama arasındaki farkın önemlilik testi ile değerlendirilmiştir. 


\subsection{Ankete Katılan Kişilerin Demografik Özellikleriyle İlgili Bulgular}

Toplam 64 çalışana anket uygulaması yapılmış ve anket sonucu ortaya çıkan göstergeler aşağıda sıralanmıştır. Buna göre anket uygulanan çalışanların \%68'i kadın, \%32'si erkektir (Şekil 1).

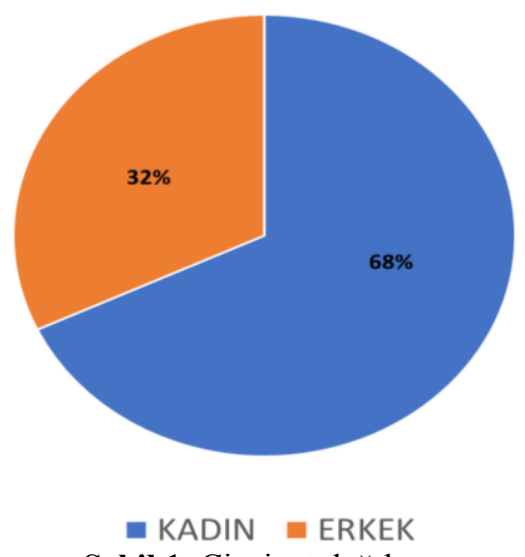

Şekil 1. Cinsiyet dağglımı

Anket uygulamasına katılan çalışanların medeni hali Şekil 2'de verilmiştir.

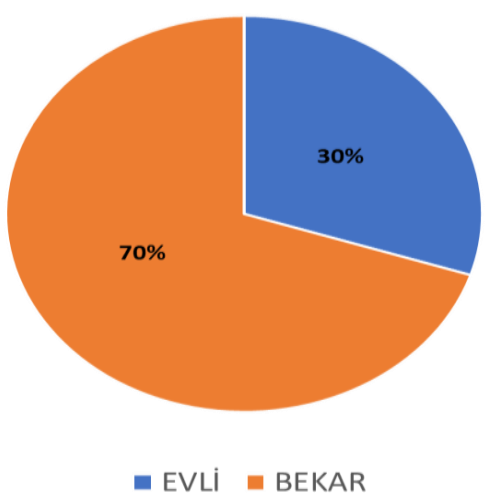

Şekil 2. Çalışanların medeni hali

İstanbul'da çeşitli sektörlerde ve farklı firmalarda çalışan kişilere yapılan anketlerde ergonomik sorunlarla karşılaşma sıklığı skoru değişkeni yönünden yaşları farklı olan iki gurubun ortalamaları Tablo 1'de karşılaştırılmış ve iki ortalama arasında istatiksel anlamda fark olup olmadığı gözlenmiștir.

\begin{tabular}{|c|c|c|c|c|c|c|c|}
\hline Yas & $\mathbf{N}$ & $\begin{array}{c}\text { Ortalama } \\
(\mathbf{X})\end{array}$ & $\begin{array}{c}\text { Standart } \\
\text { Sapma } \\
(\mathbf{S})\end{array}$ & $\mathbf{F}_{\text {hesap }}$ & $\mathbf{F}_{\text {tablo }}$ & $\mathbf{T}_{\text {hesap }}$ & $\mathbf{T}_{\text {tablo }}$ \\
\hline $\mathbf{1 8 - 3 0}$ & 34 & 23,9 & 2,1 & & & & \\
\cline { 1 - 5 } & 39 & 40,9 & 7,8 & 13,34 & 0,54 & 2.1 & $-1,6$ \\
\hline $\mathbf{3 0 +}$ & 39 & & & \\
\hline
\end{tabular}

$\mathrm{F}_{\text {hesap }}=13,34>\mathrm{F}_{\text {tablo }}=0,54$ olduğu için varyansların homojen olmadığına karar verilmiştir.

Hipotezlerin belirlenmesi;

$\mathrm{T}_{\text {hesap }}>\mathrm{T}_{\text {tablo }}=2.17>-1,66$
$\mathrm{H}_{0}$ hipotezi reddedilir ve bu sonuca göre çalışanların yaş gruplarına göre ergonomik sorunlarla karşılaşma sıklığı arasında fark olduğu kabul edilmektedir. 30+ yaş grubundaki insanların ergonomik sorunlarla karşılaşma ihtimali daha fazladır. Uzun yıllar boyunca ergonomik olarak olumsuz koşullarda çalışmış bireylerin yaşayacağı rahatsızlıklar, iş hayatına yeni başlayan insanlarla kıyaslandığında daha fazla olacağı açıktır.

\subsection{Aydınlatma}

Çalışma ortamındaki tehlikelerin görünür hale gelerek iş güvenliği şartlarının iyileşmesi ve çalışma ortamının güvenliğinin sağlanması açısından aydınlatma çok önemlidir. İş kazalarının da önüne geçilmesi konusunda aydınlatma büyük önem taşımaktadır. İşyerlerinde genellikle, aydınlatma şiddeti 200 lüksten az olduğu zaman iş kazası olma ihtimali artmaktadır. Aydınlatma ihtiyacı işyerlerinde doğal ve yapay olmak üzere ikiye ayrılmaktadır. İşyerleri tasarlanırken güneş ışığını en iyi alacak şekilde tasarlanmalıdır.

TS EN 12464 numaralı "Işıı ve 1şılklandırma- İş Mahallerinin Aydınlatılması" standardında belirtilen işyerlerindeki bazı alanlarda ve işlerde gerekli aydınlatma şiddetleri Tablo 2'de verilmektedir;

Tablo 2. Çalışma alanlarında aydınlatma değerleri [TS EN 12464]

\begin{tabular}{|c|c|}
\hline ÇALIŞMA ALANLARI & $\begin{array}{c}\text { AYDINLATMA ŞiDDETI } \\
\text { (LUX) }\end{array}$ \\
\hline Bekleme Salonları & 300 LUX \\
\hline Açık Ofisler & 750 LUX \\
\hline Toplantı Odaları & 500 LUX \\
\hline Ofisler & 500 LUX \\
\hline Rutin Ofis İşleri & 400 LUX \\
\hline Teknik Çizim Ofisleri & 750 LUX \\
\hline $\begin{array}{c}\text { Kötü Karşıt ile Çalışma } \\
\text { Resepsiyon Masası }\end{array}$ & 600 LUX \\
\hline Genel Arka Işıı & 300 LUX \\
\hline Arşivler & $160-240$ LUX \\
\hline Yol, Merdivenler & 200 LUX \\
\hline İşyerinde Açık Alanlar, Deçitler & 50 LUX \\
\hline
\end{tabular}

Yapılan çalıșmada ankete katılan kișilere işyerlerindeki aydınlatma ile ilgili bazı sorular yöneltilmiştir. Tablo 3'te çalışanların bu sorulara verdikleri cevaplar görülmektedir. 
Tablo 3. İşyerlerinde çalışanların aydınlatmaya ilişkin değerlendirmeleri

\begin{tabular}{|c|c|c|}
\hline \multicolumn{3}{|l|}{$\begin{array}{l}\text { Aydınlatma ile İlgili } \\
\text { Sorular }\end{array}$} \\
\hline $\begin{array}{c}\text { Çalışma ortamındaki } \\
\text { aydınlatmaların yeterlilik } \\
\text { durumu }\end{array}$ & $\begin{array}{c}\text { Normal } \\
\% 39,7\end{array}$ & $\begin{array}{c}\text { İyi } \\
\% 31,7\end{array}$ \\
\hline $\begin{array}{l}\text { Çalışma ortamındaki } \\
\text { aydınlatmanın çalışanı } \\
\text { rahatsız etmesi }\end{array}$ & $\begin{array}{c}\text { Nadiren } \\
\% 57,1\end{array}$ & $\begin{array}{l}\text { Genellikle } \\
\% 19\end{array}$ \\
\hline $\begin{array}{c}\text { Ortamın 1şı̆̆ına bağlı } \\
\text { olarak gözde kamaşma } \\
\text { olması }\end{array}$ & $\begin{array}{c}\text { Nadiren } \\
\% 42,9\end{array}$ & $\begin{array}{c}\text { Hiçbir } \\
\text { Zaman } \\
\% 27\end{array}$ \\
\hline $\begin{array}{l}\text { Ortamın 1şı̆̆ına bağlı } \\
\text { olarak baş ağrısı, } \\
\text { yorgunluk, bulanık görme } \\
\text { gibi durumların oluşması }\end{array}$ & $\begin{array}{c}\text { Nadiren } \\
\% 41,3\end{array}$ & $\begin{array}{l}\text { Hiçbir } \\
\text { Zaman } \\
\% 23,8\end{array}$ \\
\hline $\begin{array}{c}\text { Hangi tür aydınlatmada } \\
\text { kendinizi daha iyi } \\
\text { hissediyorsunuz? }\end{array}$ & $\begin{array}{l}\text { Doğal } \\
\% 65,1\end{array}$ & $\begin{array}{l}\text { Her İkisi de } \\
\quad \% 33,3\end{array}$ \\
\hline
\end{tabular}

Anket sonuçlarına değerlendirildiğinde, çalışma ortamındaki aydınlatmaların yeterliliği açısından ele alındığında çalışanların \%60,9'u işyerindeki aydınlatmayı yeterli bulmuştur.

Çalışma ortamında bulunan 1şık gözde olumlu ya da olumsuz etkiler yaratmaktadır. Çalışanlara ortamın 1şığına bağlı olarak gözde kamaşma olması durumu sorulduğunda sadece \%19'luk bir dilim genellikle böyle bir durumla karşılaştığını belirtmiştir.

İşyeri ortamında yanlış aydınlatmadan doğan olumsuz etkiler yalnızca göz değil, baş ağrısı, yorgunluk, bulanık görme gibi olumsuz sonuçlara da sebep olmaktadır. Yapılan anket sonuçlarına göre çalışanların \%41,3'ü ortamdaki 1şıktan kaynaklı olarak baş ağrısı, bulanık görme, yorgunluk gibi negatif sonuçlara sebep olmaktadır, ankete katılanların \%23,8'i ise hiçbir zaman böyle bir sorunla karşılaşmadığını belirtmektedir.

Gün 1şı̆̆ının işyerinin kapı, pencere gibi her türlü açık alanlarındaki boşluklardan sızarak içeri girmesini sağlayan aydınlatma türüne doğal aydınlatma denir. Gün 1şığının yetersiz olduğu durumlarda ise yapay aydınlatma kullanılmaktadır. 'Hangi tür aydınlatmada kendinizi daha rahat hissediyorsunuz?' sorusuna çalışanların \%65,1'i doğal aydınlatma cevabını vermiştir.

İnsanlar için sağlıklı olan 1ş1k kaynağ1 gün 1şı̆̆ıdır. Doğal bir aydınlatma sağlandığı zaman çalışanların kendilerini daha iyi hissettikleri gözlemlenmiştir. İsyerlerindeki olumsuz aydınlatma koşulları çalışanların iş performansını olumsuz etkilemekle birlikte aynı zamanda sağlık sorunlarıyla da iliş̧ilendirilmektedir. Görsel rahatsılıklar olarak bahsedilen bu rahatsılıklar arasında, aydınlatmanın hatalı oluşundan kaynaklanan göz yorgunluğu da yer almaktadır. Yanlış aydınlatma sonucu çalışanlarda; baş ağrıs1, göz kuruluğu, göz yaşarması, göz tahrişi, göz kaşıntısı, görme bulanıklığı gibi sorunlar ortak olarak görülmektedir. Çalışanların işyerlerinde bulunan tehlikeleri fark edebilmeleri için aydınlatma seviyelerinin belirlenen asgari seviyede olması gerekmektedir. Ortamdaki aydınlatma iyileştikçe, çalışanlar yaptıkları işleri daha net görecektir. Amerikan Ulusal Güvenlik Konseyi'nin paylaştığ rapora göre yaşanan iş kazalarının \%5'inin sebebi kötü aydınlatmadır ve kötü aydınlatma nedeniyle oluşan göz yorgunluğuyla beraber bu oran \%20'ye çıkmaktadır. Amerika'da bir sanayide yapılan çalışmada aydınlatma seviyelerinde iyileştirme yapıldıktan sonra iş kazası oranında \%32'lik bir düşüş gözlemlenmiştir [7].

İş kazalarının oluşumunda birçok etken vardır fakat işyerlerinde yeterli aydınlatma sağlandığı zaman iş kazlarının büyük çoğunluğu önlenmektedir. Yetersiz aydınlatma sonucunda en sık görülen kazalar; kayma, takılma ya da düşme kazalarıdır. Şekil 3'te de görüldüğü gibi yaralanma en çok 250 lüksün altındaki aydınlatma düzeylerinde yaşanmaktadır.

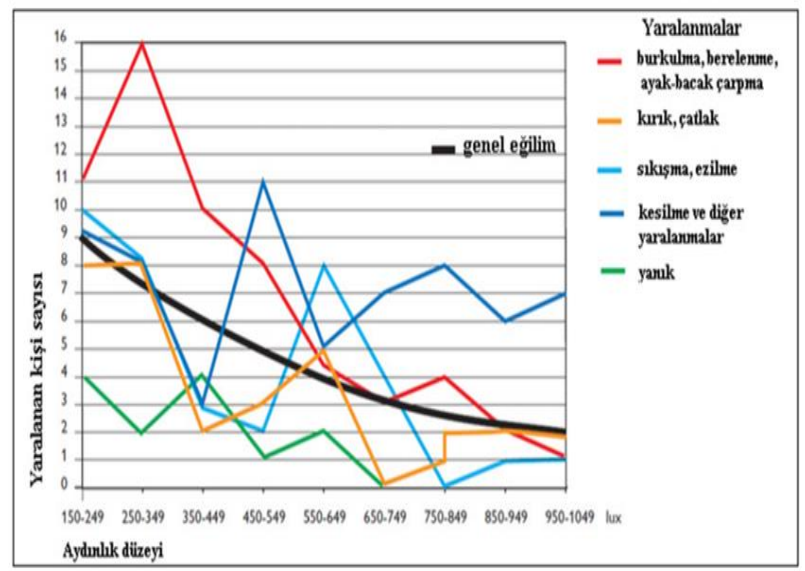

Şekil 3. Aydınlık düzeyine göre farklı endüstrilerde iş kazası sayıları [7]

Yukarıda da görüldüğü gibi yetersiz aydınlatma birçok türde kazaya ve bu kazalarda farklı çeşitlerde yaralanmaya neden olmaktadır. Şekil 3 incelendiğinde yetersiz aydınlatmadan dolayı kişilerin en çok burkulma, ayak-bacak çarpma gibi yaralanma türüyle karşılaştı̆̆ 1 görülmektedir.

Ayrıca ortam aydınlatmasının değerlendirmesi yaş çeşitli yaş gruplarına göre de değişmektedir. Yapılan anket çalışmasının sonucu, iki ortalama arasındaki farkın önemlilik testi yöntemi uygulanarak aşağıdaki sonuçlarla desteklenmiştir. Yapılan test farklı aralıklardaki yaş grupları ve çalışma sürelerinin değişimine bağlı olarak aydınlatma koşullarındaki maruziyet arasında fark olup olmadığı Tablo 4'te incelenmiştir. 
Tablo 4. Yaş gruplarına göre çalışma ortamındaki aydınlatmaların yeterlilik skoru verileri

\begin{tabular}{|c|c|c|c|c|c|c|c|}
\hline Yaş & $\mathbf{N}$ & $\begin{array}{c}\text { Ortalama } \\
(\mathbf{X})\end{array}$ & $\begin{array}{c}\text { Standart } \\
\text { Sapma } \\
(\mathbf{S})\end{array}$ & $\mathbf{F}_{\text {hesap }}$ & $\mathbf{F}_{\text {tablo }}$ & $\mathbf{T}_{\text {hesap }}$ & $\mathbf{T}_{\text {tablo }}$ \\
\hline $\begin{array}{c}\mathbf{1 8}- \\
\mathbf{3 0}\end{array}$ & 22 & 31.5 & 4,75 & & & & \\
& 11 & 17 & 3 & 2,50 & 0,55 & 2.15 & $-1,69$ \\
\hline
\end{tabular}

$F_{\text {Hesap }} 2.50>F_{\text {Tablo=-1,69 olduğu için varyansların }}$ homojen olmadığına karar verilir

$\mathrm{T}_{\text {hesap }}=2.15>\mathrm{T}_{\text {tablo }}=-1,69$

$\mathrm{H}_{0}$ hipotezi reddedilir ve bu sonuca göre çalışanların yaş gruplarına göre işyeri ortamında aydınlatmaların yeterliliğinden kaynaklı sorunlarla karşılaşma sıklığ arasında fark olduğu kabul edilmektedir. 30+ yaş grubundaki insanların aydınlatma ile ilgili sorunlarla karşılaşma ihtimali daha fazladır. Yaş ilerledikçe gözün görme yetisi de düşmektedir. Yaş gruplarına göre gereken aydınlatma miktarı farklıdır. Yapılan bir araştırma sonucu 40 yaşındaki bir bireyin kitap okurken ihtiyacı olan aydınlatma değeri 1 olarak belirlenmiştir [7]. Yaşa göre bu değerler Tablo 5'te de belirtildiği gibi farklılık göstermektedir.

Tablo 5. Yaş sınırlarına göre gerekli aydınlatma

\begin{tabular}{|c|c|c|c|c|c|}
\hline Yaş sınırı & $10-20$ & $20-30$ & $30-40$ & $40-50$ & $50-60$ \\
\hline $\begin{array}{c}\text { Aydınlatma } \\
\text { düzeyi }\end{array}$ & $0.3-0.5$ & $0.5-0.7$ & $0.7-1.0$ & $1.0-2.0$ & $2.0-5.0$ \\
\hline
\end{tabular}

Çalışanların iş hayatında geçirdikleri süreler farklılık göstermektedir. Uzun yıllar çalışan bir kişi ile iş hayatına yeni başlayan kişinin yaşadığı göz problemleri arasında farklar bulunmaktadır. Tablo 6'da kişilerin çalışma sürelerine göre ortam ışığından kaynaklı olarak yaşadıkları problemler açısından fark olup olmadığı ele alınmıştır.

Tablo 6. Çalışma sürelerine göre çalışma ortamının 1şığına bağlı olarak baş ağrısı, yorgunluk, bulanık görme gibi durumların oluşması skoru verileri

\begin{tabular}{|c|c|c|c|c|c|c|c|}
\hline Yaş & $\mathbf{N}$ & $\begin{array}{c}\text { Ortalama } \\
(\mathbf{X})\end{array}$ & $\begin{array}{c}\text { Standart } \\
\text { Sapma(S) }\end{array}$ & $\mathbf{F}_{\text {hesap }}$ & $\mathbf{F}_{\text {tablo }}$ & $\mathbf{T}_{\text {hesap }}$ & $\mathbf{T}_{\text {tablo }}$ \\
\hline $\begin{array}{c}\mathbf{0 - 1 0} \text { Yıl } \\
\text { (Hiçbir } \\
\text { Zaman) }\end{array}$ & 10 & 25,5 & 7,75 & & & & \\
\cline { 1 - 4 } $\begin{array}{c}\mathbf{1 0}+\text { Yıl } \\
\text { (Nadiren) }\end{array}$ & 13 & 18 & 2,5 & 9,61 & 0,32 & 0,63 & $-1,72$ \\
\hline
\end{tabular}

$F_{\text {Hesap }=9,61>} F_{\text {Tablo }}=0,32$ olduğu için varyansların homojen olmadığına karar verilir.

$\mathrm{T}_{\text {hesap }}=0,63>\mathrm{T}_{\text {tablo }}=-1,72$

$\mathrm{H}_{0}$ hipotezi reddedilir ve bu sonuca göre çalışanların çalışma sürelerine bakıldığı zaman çalışan kişilerin ortamın 1şığına bağlı olarak baş ağrısı, yorgunluk, bulanık görme gibi durumların oluşması sılklığ arasında fark olduğu kabul edilmektedir. Çalışma süresi fazla olan kişilerde ortamın 1şığına bağlı olarak sorun yaşama ihtimali daha fazladır. Uzun yıllar ekranlı araçlarla çalışan kişilerde gözde yıpranma yaşanması ve göze bağlı sağlık sorunları yaşanması riski daha yüksektir. Aynı durum iş hayatında uzun yıllar çalışan kişiler için de geçerlidir.

\section{SONUÇLAR}

Teknolojideki gelişmelerle birlikte yeni iş sektörleri ortaya çıkmış ve bunun sonucu olarak işgücü ihtiyacı artmıştır. Bunlara paralel olarak insana verilen önem fazlalaşmış, çalışanların işyerlerinde sağlığına ve güvenliğine dikkat edilmeye başlanmıştır. Çalışanlara işyerlerinde daha iyi çalışma şartları sunulduğu zaman işlerinde daha verimli oldukları gözlenmiştir. Tüm bu sebeplerden dolayı yapılan işin insana, insanın da işe uyumlu olması konusunda planlamalar yapılmıştır. Ergonomi, çalışma şartlarının insana göre düzenlenmesini sağlayarak işyerlerinin ve çalışanın verimini arttırmayı amaçlayan bilim dalıdır.

Yapılan bu çalışmada işyerlerinde olması gereken ergonomik koşullardan, çalışma ortamındaki aydınlatmadan kaynaklanan olumsuz koşullar, bu olumsuz koşulların kişilerin sağlığına etkisinden bahsedilmiştir.

$\mathrm{Bu}$ araştırma ergonomik koşulların çeşitli sektörlerde ve yaş gruplarında farklı etkiler yaratıp yaratmadığını ölçmek amacıyla gerek sahada gerekse ofis ortamında olmak üzere çeşitli sektörlerde çalışan kişilere uygulanmıştır. Hazırlanan anket soruları her çalışana uygulanmış, sonuçları anlamlandırabilmek adına kişiler yaş gruplarına göre ve toplam çalışılan mesleki tecrübe süresine göre iki grupta ele alınmıştır. Yaş gruplarına ve toplam çalışılan mesleki süreye göre aydınlatma ile ilgili sorulara verilen cevaplara bakılınca iki grubun verdiği cevaplar arasında farklılık olduğu iki ortalamanın farkı testiyle ortaya konmuştur.

İşyerlerinin ergonomik olarak düzenlenmesi çalışma koşulları açısından önem taşımaktadır. İşyerlerini düzenlerken aydınlatma, ısıtma ve soğutma sistemleri, havalandırma sistemleri, ses düzeyinin ayarlanması için gürültü yalıtımı yapılarak çalışanlara uygun hale getirilmelidir. Aydınlatma çalışma ortamında güvenli ve sağlıklı bir şekilde çalışabilmek için çok önemlidir. İş kazalarının oluşmasında ortamdaki aydınlatma yetersizliğinin etkisi büyüktür. Anket sorularının yöneltildiği alışanların işyerlerinde genel olarak aydınlatma sorunu ve bu sorundan kaynaklı gözde sağlık problemleri yaşanmadığı görülmektedir. Çalışılan ortamda genellikle aydınlatma seviyesi 200250 lüksten aşağı düştüğü zaman iş kazası riski arttığı için bu değerlerin altına inmemeye dikkat edilmelidir. İşverenler çalışanlarına sağlıklı ve güvenli işyeri ortamı sağlamak zorundadır. $\mathrm{Bu}$ sebeple işverenler 
çalışanların sağlıklı olarak çalışabilmesi için gerekli aydınlatma değerini sağlamakla yükümlüdür.

İşyerlerinde iş sağlığı ve güvenliği bilincinin oluşmasıyla kanunla da zorunlu hale gelen iş sağlığı ve güvenliği eğitimleri düzenli olarak verilmekte ve çalışanlarda iş güvenliği bilinci oluşturulmaktadır. Fakat ergonomi konusunda çoğu çalışan bilinçlendirilmediği için ergonomik sorunlardan dolayı yaşanan sağlık sorunları meydana gelmektedir. $\mathrm{Bu}$ yüzden ergonomi konusunda eğitim vermek çalışanları bu konuda bilinçlendirmek gerekmektedir.

Ergonomik olmayan çalışma koşulları çalışanlarda çeşitli davranışlara sebep olmaktadır. $\mathrm{Bu}$ tür davranışlar, iş kazaları, meslek hastalıkları, çalışanın işinde başarısız olması, stres, odaklanma sorunu gibi davranışlara neden olmaktadır. Ergonomik olmayan çalışma koşulları, kişileri olumsuz yönde etkilemekte bu da iş veriminin düşmesine neden olmaktadır.

Ergonomi çalışanların iş yaparken daha az yorulmasını sağlayarak karşılaşılan iş kazası ve meslek hastalığı oranını düşürmekte, insanı ve insanın çalışma şartlarını ön plana çıkarmaktadır. Aynı zamanda ergonomi tüm bunları gerçekleştirirken verimi de arttırmaktadır. Ergonomik çalışma koşulları ülkenin kalkınması için büyük bir ekonomik faktör haline gelmiştir. Ergonomi bilincinin tüm ülkede yaygınlaştırılması yaşam tarzı haline gelmesi gerekmektedir.

Sonuç olarak çalışanların rahat edebileceği ergonomik çalışma ortamları oluşturulduğunda, verimli çalışmalar beraberinde gelecektir. Bürolardaki iç tasarım uzman kişilerin yönetiminde yapılırsa birçok sıkıntının baştan önüne geçilmiş olacaktır. Bunun sonucunda kurumlar hedeflediği hizmet başarısını yakalayacaktır.

\section{KAYNAKLAR}

[1] Bayrakçıoğlu, E. (2018). Bilgisayar Kullanıcılarının Çalışma Koşullarının İncelenmesi. Yüksek Lisans Tezi, İzmir Katip Çelebi Üniversitesi, İzmir, Türkiye, 1-29.

[2] Turan, Ö. (2016). Ofis Çalışmalarında Ergonomik Risklerin İş Sağlığı ve Güvenliği Açısından Değerlendirilmesi. Yüksek Lisans Tezi, İstanbul Aydın Üniversitesi İş Sağlığı ve Güvenliği Ana Bilim Dalı, İstanbul, Türkiye, 10-37.

[3] Kıraç, Y. (2005). Büro Yönetiminde Ergonomi ve Ergonominin Verimliliğe Etkisi: Ankara Emniyet Müdürlüğü'nde Bir Uygulama. T.C. Gazi Üniversitesi Eğitim Bilimleri Enstitüsü Büro Yönetimi Ana Bilim Dalı. Ankara, Türkiye, 10-12.

[4] Bilgiç, E. (2013). İşyerinde Ergonomik Risklerin Değerlendirilmesi; Tehlikeli Sınıfta Yer Alan Bir Fabrikanın Üretim Sahalarında Çalışan Kişilerin Kas İskelet Sistemi Yakınmaları Ve Etkileyen Faktörlerin İncelenmesi. Yüksek Lisans Tezi, T.C Marmara Üniversitesi Sağlık Bilimleri Enstitüsü. İstanbul, Türkiye, 3-4.

[5] http://help.planports.com/Blog/Post/likert-olceginedir, 2014.

[6] Efe, N. (2016). Büroların Ergonomik Açıdan Düzenlenmesinin Verimlilik Açısından Rolü, Yüksek Lisans Tezi, T.C Gazi Üniversitesi Eğitim Bilimleri Enstitüsü, Ankara, Türkiye, 28-44.

[7] Bayraktar, G. (2016). İşyerlerinin Aydınlatma Koşullarının İş Sağlığı ve Güvenliği Yönünden Değerlendirilmesi, İş Sağlığı ve Güvenliği Uzmanlık Tezi, T.C Çalışma ve Sosyal Güvenlik Bakanlığı İş Sağlığı ve Güvenliği Genel Müdürlüğü, Ankara, Türkiye, 7-20. 